\title{
Negative Public Attitudes towards Cancer Survivors Returning to Work: A Nationwide Survey in Korea
}

\author{
Hye-Young Shim, $\mathrm{PhD}^{1}$ \\ Ji-Yeon Shin, MD, PhD² \\ Jong Heun Kim, MD, PhD \\ So-Young Kim, MD, PhD ${ }^{3}$ \\ Hyung-Kook Yang, MD, MPH ${ }^{\top}$ \\ Jong-Hyock Park, MD, PhD
}

${ }^{1}$ National Cancer Control Institute, National Cancer Center, Goyang,

${ }^{2}$ Department of Preventive Medicine,

Eulji University School of Medicine, Daejeon,

${ }^{3}$ College of Medicine/Graduate

School of Health Science Business

Convergence, Chungbuk National University

Cheongju, Korea

\begin{abstract}
Purpose
Early diagnosis and an improved survival rate have emerged as important issues for cancer survivors returning to work during the prime of their working life. This study investigated the attitudes of the general public towards cancer survivors returning to work in Korea and attempted to identify the factors influencing this negative attitude.
\end{abstract}

\section{Materials and Methods}

A general public perception survey regarding cancer survivors returning to work, targeting 2,000 individuals between 40-70 years of age, was conducted as face-to-face home visit.

\section{Results}

The public expressed a negative attitude towards cancer survivors returning to work, in terms of both perception and acceptance. Negative perception was higher among those in metropolitan areas compared with urban/rural areas (odds ratio [OR], 1.71), with monthly incomes $<\$ 2,000$ compared with $>\$ 4,000$ (OR, 1.54), and with patient care experience compared with those without $(\mathrm{OR}, 1.41)$. Negative acceptance was higher among those with monthly incomes $<\$ 2,000$ compared with $>\$ 4,000$ (OR, 1.71) and those with patient care experience compared with those without (OR, 1.54). The common factors between acceptance and perception that influenced negative attitude included area of residence, patient care experience, and monthly income.

\section{Conclusion}

This study identified negative attitudes towards cancer survivors returning to work in South Korea and the factors influencing the reintegration of cancer survivors into society. It is necessary to promote community awareness and intervention activities to enable access to community, social, and individual units for the social reintegration of cancer survivors.
Correspondence: Jong-Hyock Park, MD, PhD College of Medicine/Graduate

School of Health Science Business Convergence,

Chungbuk National University,

776 ilsunhwan-ro, Heungdeok-gu,

Cheongju 28644, Korea

Tel: 82-43-261-2873

Fax: 82-43-261-3459

E-mail: Jonghyock@gmail.com

Received March 4, 2015

Accepted April 22, 2015

Published Online June 5, 2015
Key words

Attitude, Return to work, Survivors, Social stigma

\section{Introduction}

Early diagnosis combined with improved cancer treatments has increased the lifespan of most patients (up to 65\%) to more than 5 years from the time of diagnosis. Due to screening and treatment improvements, it is estimated that there are over 1 million cancer survivors in South Korea [1]. The prevalence of cancer increases with age although $47.3 \%$ of cancer patients are diagnosed between the ages of 20-60 years [1]. These survivors are in their working prime; therefore cancer diagnosis has an effect on employment [2]. A cohort study of South Korean cancer patients found that $47 \%$ lost their jobs after being diagnosed with cancer and only $30.5 \%$ returned to work [3]. While the global average return to work rate for cancer survivors is $63.5 \%$ (ranging from $24 \%$ to $94 \%$ ) [4], the rate for Koreans is only half that.

Many cancer survivors experience problems with employment and discrimination in social activities due solely to having cancer, which affects their quality of life (including 


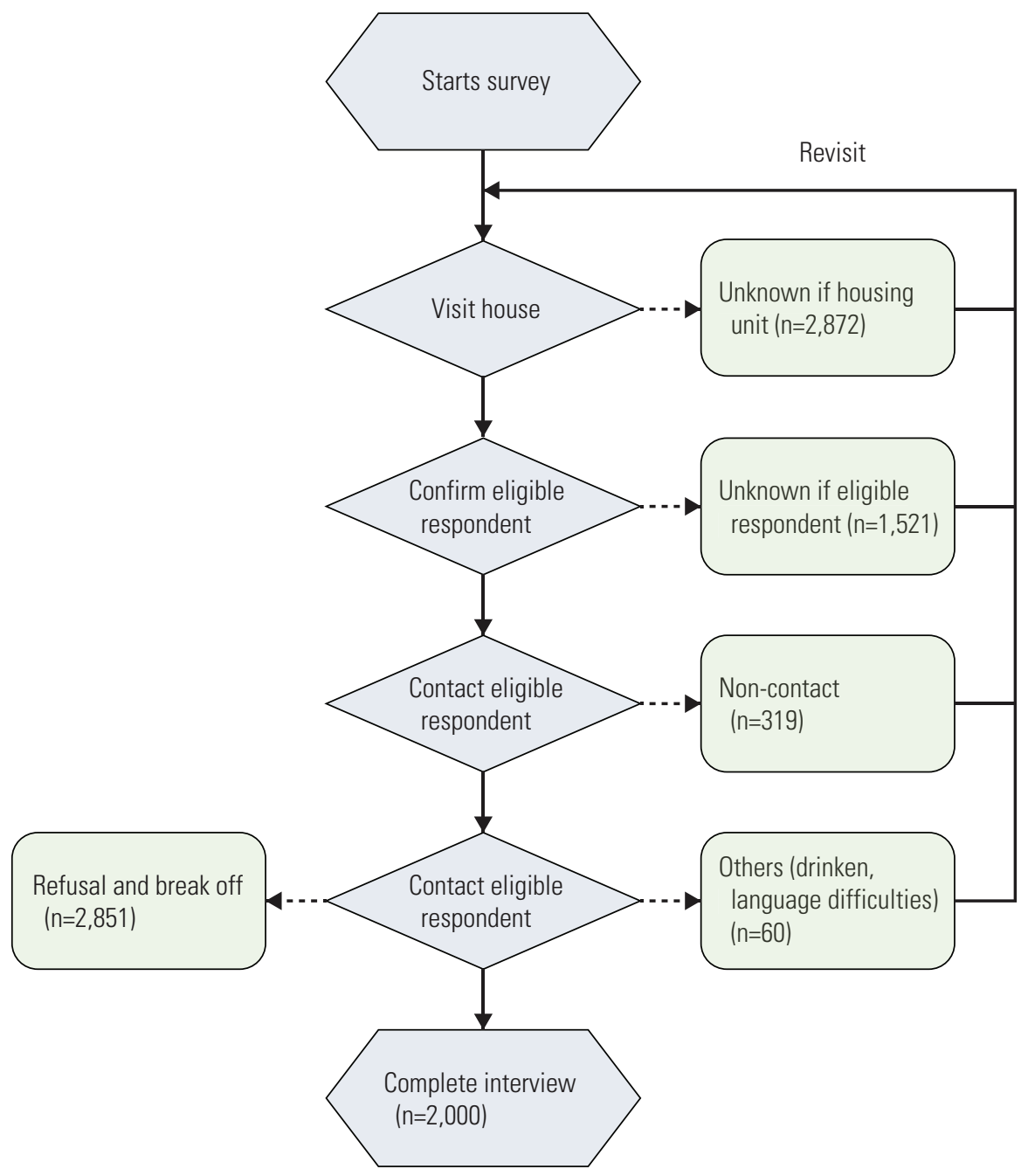

Fig. 1. Flow chart of study population.

employment) [5]. In the United States especially, nearly $18.0 \%$ of cancer survivors experienced employment difficulties due to having cancer [5].

Whether cancer survivors can lead successful lives in their local communities depends on general public understanding and active acceptance of their situation [6]. The negative attitudes of the public can lead to negative decision-making, excluding certain groups from social participation, thereby alienating them from society. However, few studies of public attitudes towards cancer survivors returning to work based on social and cultural factors have been conducted. Previous studies have assessed the existing attitudes of the public towards cancer survivors returning to work. However, an analysis by Chen et al. [2] was not able to identify the factors responsible for the negative attitude of the public in Singapore, and Cho et al. [7] was not enough to deal with the return to the work issues of cancer stigma in Korea. This marks the first study to evaluate, using a nationwide survey, the negative attitudes of the public towards cancer survivors returning to work and the factors that influence those attitudes.

\section{Materials and Methods}

\section{Study design and population}

To investigate public attitudes towards cancer survivors returning to work, 2,000 people 40-70 years of age were surveyed from November 1 to December 31, 2012. Using strati- 
Table 1. Exploratory factor analysis of public attitudes towards cancer survivors

\begin{tabular}{|c|c|c|c|}
\hline & Factor 1 & Factor 2 & Mean \pm SD \\
\hline Cancer patients should retire early & 0.704 & -0.036 & $2.34 \pm 0.78$ \\
\hline Since cancer patients feel weak, their coworkers may feel weak as well & 0.700 & 0.018 & $2.39 \pm 0.83$ \\
\hline Companies should consider cancer patients first during layoffs & 0.700 & -0.059 & $2.25 \pm 0.77$ \\
\hline $\begin{array}{l}\text { Since cancer patients are less competitive, they should depend on their families, } \\
\text { instead of re-entering society }\end{array}$ & 0.689 & 0.093 & $2.37 \pm 0.81$ \\
\hline Trouble working due to post-treatment depression in cancer patients & 0.681 & 0.144 & $2.67 \pm 0.81$ \\
\hline Less confidence at work among cancer patients & 0.681 & 0.109 & $2.58 \pm 0.84$ \\
\hline Poor performance of cancer patients due to lack of concentration and memory loss & 0.677 & 0.107 & $2.72 \pm 0.80$ \\
\hline Companies should hire healthy new employees rather than experienced cancer patients & 0.657 & 0.078 & $2.53 \pm 0.80$ \\
\hline Lower ability of cancer patients to work due to pain after treatment & 0.621 & 0.137 & $2.81 \pm 0.72$ \\
\hline Feelings of discomfort when seeing wigs and hats on cancer patients during work & 0.616 & -0.102 & $2.36 \pm 0.83$ \\
\hline $\begin{array}{l}\text { Even though most cancer patients want to work, there might not be much work } \\
\text { available for them }\end{array}$ & 0.594 & -0.030 & $2.55 \pm 0.75$ \\
\hline I feel insecure about the job abilities of coworkers who have cancer & 0.419 & -0.021 & $2.47 \pm 0.71$ \\
\hline $\begin{array}{l}\text { Employees with cancer should be considerate of their coworkers by not attending } \\
\text { corporate events }\end{array}$ & 0.411 & 0.311 & $2.53 \pm 0.75$ \\
\hline $\begin{array}{l}\text { A work environment should be created such that coworkers with cancer can work as } \\
\text { ordinary employees }\end{array}$ & -0.030 & 0.626 & $3.06 \pm 0.57$ \\
\hline I agree that coworkers with cancer should be entitled to promotions & -0.109 & 0.610 & $2.93 \pm 0.63$ \\
\hline A resting place should be provided for coworkers with cancer in the workplace & 0.093 & 0.592 & $2.90 \pm 0.64$ \\
\hline I agree on a reduction in work hours for coworkers with cancer at the same pay & 0.130 & 0.565 & $2.84 \pm 0.76$ \\
\hline $\begin{array}{l}\text { I agree that coworkers with cancer should be entitled to special long-term vacations over } \\
6 \text {-month periods }\end{array}$ & 0.049 & 0.561 & $2.89 \pm 0.73$ \\
\hline Cancer patients should be given equal promotional opportunities & 0.015 & 0.453 & $2.83 \pm 0.65$ \\
\hline Eigenvalues & 5.273 & 2.143 & \\
\hline Total variance $(\%)$ & 27.753 & 11.281 & \\
\hline Cumulative variance (\%) & 27.753 & 39.035 & \\
\hline $\mathrm{KMO}=0.879$, Bartlett's $\chi^{2}=10,013.142(\mathrm{p}<0.001)$ & & & \\
\hline
\end{tabular}

$\mathrm{SD}$, standard deviation; KMO, Kaiser-Meyer-Olkin.

fied sampling, after dividing the population into strata by region, samples were allocated to strata in proportion to their population size and the three-stage systematic sampling method was employed in the same unit. Specifically, during the first stage, the population with 40-70 years of age comprising registered residents as of December 2010 was selected and categorized by sex and age. Systematic sampling was then conducted on units (districts) at fixed intervals; using a random number table, the street addresses to be surveyed were determined. During the second stage, the street addresses were selected as the primary subject households. If a household could not be reached for the survey, the next household in line was surveyed. During the third stage, an investigator from a specialized social survey service visited each household, from which one member was chosen for the interview using a structured questionnaire. The following were the exclusion criteria: the household did not have any age-qualified member and therefore no member could be interviewed $(n=2,872)$; whether the household qualified could not be confirmed because the interviewer's contact was with children $(\mathrm{n}=1,521)$; the subject was absent from home when visited at least two or three times $(n=319)$; the subject household member, although qualified, was unable to participate in an interview due to consuming alcohol or having a speech disorder $(n=60)$; the subject household member refused to cooperate when reached, even though qualified $(\mathrm{n}=2,851)$. After exclusions, we completed the survey on 2,000 people (Fig. 1). Based on the household visits in each city, the response $(20.7 \%)$, cooperation $(40.7 \%)$, refusal (29.6\%), and contact rates (51.0\%) were calculated. The predominant reasons for refusal were 'being too busy' (54.0\%), 'breach of privacy' (25.0\%), 'not comfortable answering' (17.0\%), and 'other' (4.0\%). To conduct this survey, Institutional Review Board (IRB) approval was obtained from the National Cancer Center in 2012. 
Table 2. Study subject characteristics

\begin{tabular}{|c|c|}
\hline Characteristic & No. $(\%)$ \\
\hline \multicolumn{2}{|l|}{ Sex } \\
\hline Male & $991(49.5)$ \\
\hline Female & $1,009(50.5)$ \\
\hline \multicolumn{2}{|l|}{ Age (yr) } \\
\hline$<60$ & $1,578(78.9)$ \\
\hline$>60$ & $422(21.1)$ \\
\hline \multicolumn{2}{|l|}{ Region } \\
\hline Metro & $956(47.8)$ \\
\hline City, rural & $1,044(52.2)$ \\
\hline \multicolumn{2}{|l|}{ Marital status } \\
\hline Married & $1,893(94.7)$ \\
\hline Divorced, widow & $80(4.0)$ \\
\hline Unmarried & $27(1.4)$ \\
\hline \multicolumn{2}{|l|}{ Education } \\
\hline$<$ High school & $1,364(68.2)$ \\
\hline > High school & $636(31.8)$ \\
\hline \multicolumn{2}{|l|}{ Monthly income } \\
\hline$<\$ 2,000$ & $328(16.4)$ \\
\hline$\$ 2,000-4,000$ & $1,046(52.3)$ \\
\hline$>\$ 4,000$ & $626(31.3)$ \\
\hline \multicolumn{2}{|l|}{ Religion } \\
\hline No & $921(46.0)$ \\
\hline Yes & $1,079(54.0)$ \\
\hline \multicolumn{2}{|l|}{ Care experience } \\
\hline No & $1,161(58.0)$ \\
\hline Yes & $839(42.0)$ \\
\hline \multicolumn{2}{|l|}{ Care cost } \\
\hline$<\$ 2,000$ & $1,542(77.1)$ \\
\hline$>\$ 2,000$ & $458(22.9)$ \\
\hline \multicolumn{2}{|c|}{ Cancer patients among family/friends } \\
\hline No & $1,762(88.1)$ \\
\hline Yes & $238(11.9)$ \\
\hline
\end{tabular}

\section{Measures}

This survey was conducted to investigate the attitudes of the public towards cancer survivors returning to work in Korea. Because no appropriate survey instrument for identifying these attitudes is available, the research team developed a questionnaire using the following process. In the first stage, the team referred to the literature to develop a semistructured questionnaire and devised questions via qualitative interviews with 10 cancer survivors who had completed cancer treatments (five leukemia, one stomach cancer, three breast cancer, and one colon cancer case) regarding their perceived obstacles upon return to work.

To assess the adequacy of the survey tool used to identify categorized attitudes, an exploratory factor analysis consist- ing of 19 questions regarding attitudes was conducted. This consisted of a principal component analysis; an eigenvalue of 1 was used as a criterion for factor extraction, and Varimax was applied for factor rotation (Table 1). The questionnaire consisted of 13 questions about the perception of cancer survivors returning to work and six questions regarding acceptance of cancer survivors returning to work. The questions were divided into those pertaining to respondent characteristics and to the perception and acceptance of cancer survivors returning to work. All questions were answered on a four-point Likert scale per category; each item was converted into a score (strongly disagree, 1; disagree, 2; agree, 3 ; and strongly agree, 4 ), and the average scores of the question domains were 2.36 and 2.79 , respectively. The criteria used to determine whether an attitude was negative or positive were as follows: (1) for perceptions of cancer survivors, negative if higher than the average and positive if lower than the average, and (2) for acceptance of cancer survivors, positive if higher than the average and negative if lower than the average. The respondent characteristics section included sex, age (under/ over 60 years), region (metropolitan/urban or rural area), marital status (married, divorced/widowed, unmarried), education (below high school/high school and above), monthly income $(<\$ 2,000 /$ $\$ 2,000-4,000 />\$ 4,000$ ), religion (yes/no), patient care experience (yes/no), cost of cancer patient care $(<\$ 2,000 /$ $\geq \$ 2,000$ ) and cancer patients among family/friends (yes/ no). In addition, to test the reliability of the scale employed in this study, an analysis using Cronbach's alpha was conducted. The resulting Cronbach's alpha values were 0.84 for the overall scale, 0.88 for perceptions regarding the return to work, and 0.60 for acceptance of cancer survivors.

\section{Statistical analysis}

To identify the general characteristics of the respondents who participated in the survey, a frequency analysis was conducted. To identify the factors that influence perceptions about returning to work and acceptance of cancer survivors, a univariate logistic regression analysis was performed. In the univariate model, socio-demographic factors such as age, sex, education, marital status, monthly income, residence, and religion were included. The independent variables included the existence of cancer patients among family/ friends, cost of cancer patient care, and patient care experience, and the dependent variables included the negative and positive responses. The multivariate analysis was performed in two stages: in model 1, socio-demographic factors (age, sex, education, marital status, monthly income, residence, and religion) were included as covariates, regardless of the results of a bivariate analysis; in model 2 , additional variables such as existence of cancer patients among friends, cost of 
Table 3. Public attitudes toward cancer survivors regarding return to work

\begin{tabular}{|c|c|c|c|c|c|}
\hline \multirow[b]{2}{*}{ Survey questionnaire } & \multicolumn{4}{|c|}{ No. $(\%)$} & \multirow{2}{*}{$\begin{array}{l}\text { Average } \\
\text { (SE) }\end{array}$} \\
\hline & $\begin{array}{l}\text { Strongly } \\
\text { disagree }\end{array}$ & Disagree & Agree & $\begin{array}{l}\text { Strongly } \\
\text { agree }\end{array}$ & \\
\hline \multicolumn{6}{|l|}{ Perceptions towards cancer survivors returning to work } \\
\hline Lower ability of cancer patients to work due to pain after treatment & $72(3.6)$ & $522(26.1)$ & $1,119(56.0)$ & $287(14.4)$ & $2.81(0.016)$ \\
\hline $\begin{array}{l}\text { Poor performance of cancer patients due to lack of concentration and } \\
\text { memory loss }\end{array}$ & $108(5.4)$ & $675(33.8)$ & $894(44.7)$ & $323(16.2)$ & $2.72(0.018)$ \\
\hline Trouble working due to post-treatment depression in cancer patients & $113(5.7)$ & $748(37.4)$ & $824(41.2)$ & $315(15.8)$ & $2.67(0.018)$ \\
\hline $\begin{array}{l}\text { Feelings of discomfort when seeing wigs and hats on cancer patients } \\
\text { during work }\end{array}$ & $293(14.7)$ & $861(43.1)$ & $685(34.3)$ & $161(8.1)$ & $2.36(0.018)$ \\
\hline Since cancer patients feel weak, their coworkers may feel weak as well & $274(13.7)$ & $850(42.5)$ & $701(35.1)$ & $175(8.8)$ & $2.39(0.019)$ \\
\hline Less confidence at work among cancer patients & $200(10.0)$ & $694(34.7)$ & $846(42.3)$ & $260(13.0)$ & $2.58(0.019)$ \\
\hline $\begin{array}{l}\text { Even though most cancer patients want to work, there might not be } \\
\text { much work available for them }\end{array}$ & $141(7.1)$ & $787(39.4)$ & $900(45.0)$ & $172(8.6)$ & $2.55(0.017)$ \\
\hline $\begin{array}{l}\text { Since cancer patients are less competitive, they should depend on } \\
\text { their families, instead of re-entering society }\end{array}$ & $279(14.0)$ & $850(42.5)$ & $724(36.2)$ & $147(7.4)$ & $2.37(0.018)$ \\
\hline Cancer patients should retire early & $270(13.5)$ & $893(44.7)$ & $721(36.1)$ & $116(5.8)$ & $2.34(0.017)$ \\
\hline $\begin{array}{l}\text { Companies should hire healthy new employees rather than } \\
\text { experienced cancer patients }\end{array}$ & $188(9.4)$ & $778(38.9)$ & $826(41.3)$ & $208(10.4)$ & $2.53(0.018)$ \\
\hline Companies should consider cancer patients first during layoffs & $314(15.7)$ & $977(48.9)$ & $610(30.5)$ & $99(5.0)$ & $2.25(0.017)$ \\
\hline I feel insecure about the job abilities of coworkers who have cancer & $102(5.1)$ & $998(49.9)$ & $754(37.7)$ & $146(7.3)$ & $2.47(0.016)$ \\
\hline $\begin{array}{l}\text { Employees with cancer should be considerate of their coworkers by } \\
\text { not attending corporate events }\end{array}$ & $159(8.0)$ & $772(38.6)$ & $919(46.0)$ & $150(7.5)$ & $2.53(0.017)$ \\
\hline \multicolumn{6}{|l|}{ Acceptance of cancer survivors returning to work } \\
\hline $\begin{array}{l}\text { A work environment should be created such that coworkers with } \\
\text { cancer can work as ordinary employees }\end{array}$ & $10(0.5)$ & $231(11.6)$ & $1,383(69.2)$ & $376(18.8)$ & $3.06(0.013)$ \\
\hline $\begin{array}{l}\text { I agree on a reduction in work hours for coworkers with cancer at } \\
\text { the same pay }\end{array}$ & $68(3.4)$ & $561(28.1)$ & $997(49.9)$ & $374(18.7)$ & $2.84(0.017)$ \\
\hline $\begin{array}{l}\text { I agree that coworkers with cancer should be entitled to special } \\
\text { long-term vacations over 6-month periods }\end{array}$ & $57(2.9)$ & $489(24.5)$ & $1,070(53.5)$ & $384(19.2)$ & $2.89(0.016)$ \\
\hline I agree that coworkers with cancer should be entitled to promotions & $29(1.5)$ & $383(19.2)$ & $1,295(64.8)$ & $293(14.7)$ & $2.93(0.014)$ \\
\hline Cancer patients should be given equal promotional opportunities & $45(2.3)$ & $482(24.1)$ & $1,240(62.0)$ & $233(11.7)$ & $2.83(0.014)$ \\
\hline $\begin{array}{l}\text { A resting place should be provided for coworkers with cancer in } \\
\text { the workplace }\end{array}$ & $27(1.4)$ & $445(22.3)$ & $1,232(61.6)$ & $296(14.8)$ & $2.9(0.014)$ \\
\hline
\end{tabular}

SE, standard error.

cancer patient care, and patient care experience were included. Data from patients with missing values were excluded from the multiple logistic regression model. All statistical analyses were conducted using SPSS ver. 12.0 (SPSS Inc., Chicago, IL). Two-tailed null hypotheses of no difference were rejected if $\mathrm{p}$-values were less than 0.05 , or, equivalently, if the $95 \%$ confidence intervals (CIs) of risk point estimates excluded 1.

\section{Results}

\section{Population characteristics}

The characteristics of the respondents to this survey were as follows: 1,009 (50.5\%) were female, 1,579 (78.9\%) were under the age of 60 years, 1,044 (52.2\%) lived in urban/ rural areas, $1,364(68.2 \%)$ had an education level below high school, $626(31.3 \%)$ earned $>\$ 4,000 / \mathrm{mo}, 839(42.0 \%)$ had cancer patients among their friends, $458(22.9 \%)$ had patient care experience, and 1,762 $(81 \%)$ paid $<\$ 2,000$ for medical treatment (Table 2). 
$(\%)$

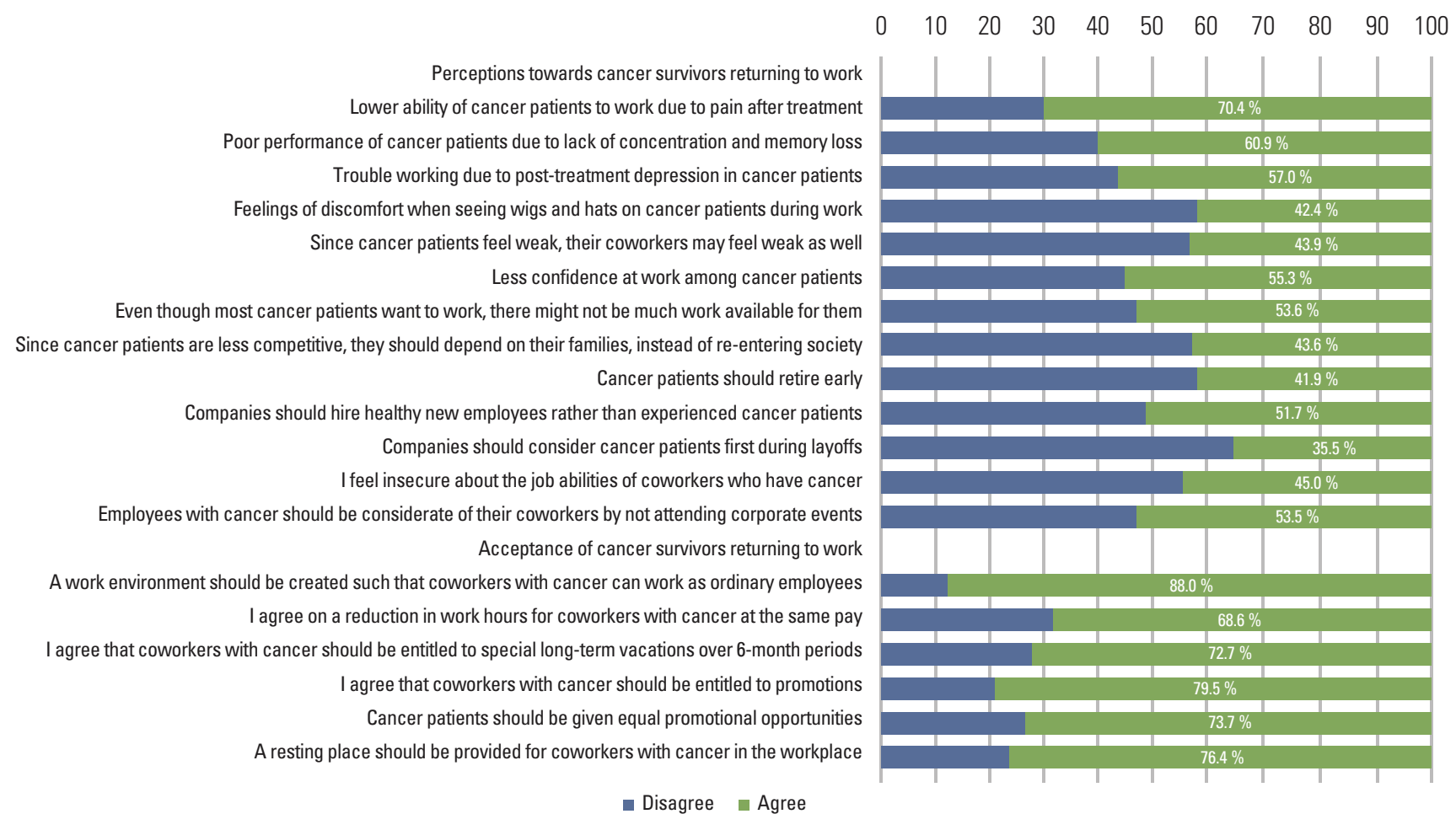

Fig. 2. Negative public attitudes towards cancer survivors returning to work.

\section{Attitudes towards cancer survivors returning to work}

Among the survey questions on the perceptions towards cancer survivors returning to work, negative answers prevailed: cancer patients are expected 'to be less efficient at work due to pain' (70.4\%), 'to perform poorly due to lack of concentration and memory loss' $(60.9 \%)$, 'to have trouble working due to post-treatment depression' (57.0\%), and 'to be less confident about their work' (55.3\%). With regard to the acceptance of cancer survivors in the workplace, there were largely positive responses towards 'creating a work environment that will allow coworkers with cancer to work as regular employees' $(88.0 \%)$, 'agreement that coworkers with cancer should be entitled to promotions' (79.5\%), 'providing a resting place in the workplace for coworkers with cancer' (76.4\%), and 'giving cancer patients equal promotion opportunities' $(73.7 \%)$. However, $31.4 \%$ of the respondents disagreed with the reduction of work hours with the same pay for coworkers with cancer (Table 3, Fig. 2).

\section{Factors associated with negative attitudes towards cancer survivors returning to work}

To identify the factors associated with negative attitudes towards cancer survivors returning to work, a univariate analysis of the perception (domain 1) and acceptance (domain 2) of cancer survivor domains was conducted. Factors that significantly influenced perception $(\mathrm{p}<0.05)$ included region, marital status and monthly income, and those that influenced acceptance $(p<0.05)$ included monthly income and patient care experience. The results of the multivariate logistic regression model 2 showed that the factors associated with a negative perception towards cancer survivors returning to work included area of residence, monthly income and patient care experience. Negative perceptions were higher in urban/rural areas than in metropolitan areas (odds ratio [OR], 1.71; 95\% CI, 1.42 to 2.06); negative perceptions were higher among those who earn $>\$ 4,000$ than those who earn < $\$ 2,000$ (OR, 1.54; 95\% CI, 1.11 to 2.14); and negative attitudes were higher among those who had patient care experience than those who did not (OR, 1.41; $95 \% \mathrm{CI}, 1.11$ to 1.78). Negative public acceptance of cancer survivors returning to work was higher among those who earn $>\$ 4,000$ compared with those who earn $<\$ 2,000$ (OR, $1.71 ; 95 \%$ CI, 1.24 to 2.37), and negative acceptance was higher among those who had patient care experience than those who did not (OR, $1.54 ; 95 \%$ CI, 1.24 to 2.37 ) (Tables 4 and 5). 
Table 4. Factors associated with public negative perception towards cancer survivors

\begin{tabular}{|c|c|c|c|c|c|c|}
\hline \multirow{2}{*}{ Characteristic } & \multicolumn{2}{|c|}{ Unadjusted } & \multicolumn{2}{|c|}{ Adjusted model 1} & \multicolumn{2}{|c|}{ Adjusted model 2} \\
\hline & OR & $95 \% \mathrm{CI}$ & OR & $95 \% \mathrm{CI}$ & OR & $95 \% \mathrm{CI}$ \\
\hline \multicolumn{7}{|l|}{ Sex } \\
\hline Male & 1 & Reference & 1 & Reference & 1 & Reference \\
\hline Female & 0.88 & $0.74-1.05$ & 0.89 & $0.74-1.07$ & 0.86 & $0.71-1.03$ \\
\hline \multicolumn{7}{|l|}{ Age (yr) } \\
\hline$<60$ & 1 & Reference & 1 & Reference & 1 & Reference \\
\hline$>60$ & 0.85 & $0.69-1.06$ & 0.97 & $0.75-1.25$ & 0.98 & $0.76-1.27$ \\
\hline \multicolumn{7}{|l|}{ Region } \\
\hline Metro & 1 & Reference & 1 & Reference & 1 & Reference \\
\hline City, rural & 1.66 & $1.39-1.98^{\star * *}$ & 1.74 & $1.44-2.09^{* * *}$ & 1.71 & $1.42-2.06^{* * *}$ \\
\hline \multicolumn{7}{|l|}{ Marital status } \\
\hline Married & 1 & Reference & 1 & Reference & 1 & Reference \\
\hline Divorced, widow & 0.61 & $0.38-0.97$ & 0.68 & $0.42-1.10$ & 0.67 & $0.41-1.08$ \\
\hline Unmarried & 1.34 & $0.62-2.87$ & 1.40 & $0.64-3.06$ & 1.43 & $0.65-3.13$ \\
\hline \multicolumn{7}{|l|}{ Education } \\
\hline$<$ High school & 1 & Reference & 1 & Reference & 1 & Reference \\
\hline$>$ High school & 0.94 & $0.78-1.14$ & 0.85 & 0.69-1.04 & 0.85 & 0.69-1.05 \\
\hline \multicolumn{7}{|l|}{ Monthly income } \\
\hline$<\$ 2,000$ & 1 & Reference & 1 & Reference & 1 & Reference \\
\hline$\$ 2,000-4,000$ & 1.33 & $1.04-1.71$ & 1.29 & $0.97-1.72$ & 1.28 & $0.96-1.71$ \\
\hline$>\$ 4,000$ & 1.32 & $1.01-1.72$ & 1.54 & $1.11-2.13$ & 1.54 & $1.11-2.14^{* *}$ \\
\hline \multicolumn{7}{|l|}{ Religion } \\
\hline No & 1 & Reference & 1 & Reference & 1 & Reference \\
\hline Yes & 0.86 & $0.72-1.02$ & 0.90 & $0.75-1.08$ & 0.89 & $0.74-1.07$ \\
\hline \multicolumn{7}{|l|}{ Care experience } \\
\hline No & 1 & Reference & - & - & 1 & Reference \\
\hline Yes & 1.22 & $0.99-1.50$ & - & - & 1.41 & $1.11-1.78^{* *}$ \\
\hline \multicolumn{7}{|l|}{ Care cost } \\
\hline$<\$ 2,000$ & 1 & Reference & - & - & 1 & Reference \\
\hline$>\$ 2,000$ & 0.81 & $0.62-1.06$ & - & - & 0.73 & $0.54-1.00$ \\
\hline \multicolumn{7}{|c|}{ Cancer patients among family/friends } \\
\hline No & 1 & Reference & - & - & 1 & Reference \\
\hline Yes & 0.92 & $0.77-1.10$ & - & - & 0.96 & $0.79-1.16$ \\
\hline
\end{tabular}

OR, odds ratio; CI, confidence interval. ${ }^{* * *} \mathrm{p}<0.001,{ }^{* *} \mathrm{p}<0.01$.

\section{Discussion}

This study attempted to identify the public's negative attitudes towards cancer survivors returning to work and the factors that influence these attitudes. Much of the perception associated with cancer is hypothesized to derive from the fear of suffering and death [8]. Since it is a common disease that is often unavoidable, cancer reminds us that we too are vulnerable and mortal. Some people distance themselves from the affected individual because they fear death. Indeed, cancer patients report that social interactions can become strained and that others avoid them because they feel awk- ward and do not know what to say to someone with cancer [9]. The strained and awkward social relationships experienced by cancer patients raise an important distinction between stigma and the related construct of social constraints [10]. Social constraints are defined as a perceived inadequacy in social support, resulting in a reluctance to disclose cancerrelated thoughts and feelings [10]. In a study of the public's attitudes towards cancer patients in Korea, 71.8\% believed that cancer patients are unable to contribute to society effectively; furthermore, $50.7 \%$ responded that if they had cancer, they would not disclose it to their coworkers, leading to a lower rate of disclosure intention due to fear of discrimination and stigma [7]. In Singapore, people tend to perceive 
Table 5. Factors associated with public negative acceptance towards cancer survivors

\begin{tabular}{|c|c|c|c|c|c|c|}
\hline \multirow{2}{*}{ Characteristic } & \multicolumn{2}{|c|}{ Unadjusted } & \multicolumn{2}{|c|}{ Adjusted model 1} & \multicolumn{2}{|c|}{ Adjusted model 2} \\
\hline & OR & $95 \% \mathrm{CI}$ & OR & $95 \% \mathrm{CI}$ & OR & $95 \% \mathrm{CI}$ \\
\hline \multicolumn{7}{|l|}{ Sex } \\
\hline Male & 1 & Reference & 1 & Reference & 1 & Reference \\
\hline Female & 0.91 & $0.76-1.08$ & 1.10 & $0.92-1.32$ & 1.05 & $0.87-1.27$ \\
\hline \multicolumn{7}{|l|}{ Age (yr) } \\
\hline$<60$ & 1 & Reference & 1 & Reference & 1 & Reference \\
\hline$>60$ & 1.12 & $0.91-1.40$ & 1.06 & $0.82-1.38$ & 1.08 & $0.87-1.40$ \\
\hline \multicolumn{7}{|l|}{ Region } \\
\hline Metro & 1 & Reference & 1 & Reference & 1 & Reference \\
\hline City, rural & 1.08 & $0.91-1.29$ & 1.02 & $0.85-1.22$ & 1.01 & $0.84-1.21$ \\
\hline \multicolumn{7}{|l|}{ Marital status } \\
\hline Married & 1 & Reference & 1 & Reference & 1 & Reference \\
\hline Divorced, widow & 0.98 & $0.63-1.53$ & 1.17 & $0.73-1.85$ & 1.14 & $0.72-1.82$ \\
\hline Unmarried & 1.00 & $0.47-2.15$ & 1.18 & $0.55-2.55$ & 1.18 & $0.54-2.56$ \\
\hline \multicolumn{7}{|l|}{ Education } \\
\hline$<$ High school & 1 & Reference & 1 & Reference & 1 & Reference \\
\hline > High school & 0.87 & $0.72-1.05$ & 1.07 & $0.87-1.32$ & 1.06 & $0.86-1.31$ \\
\hline \multicolumn{7}{|l|}{ Monthly income } \\
\hline$<\$ 2,000$ & 1 & Reference & 1 & Reference & 1 & Reference \\
\hline$\$ 2,000-4,000$ & 0.89 & $0.70-1.15$ & 1.17 & $0.88-1.55$ & 1.17 & $0.88-1.56$ \\
\hline$>\$ 4,000$ & 0.61 & $0.47-0.80^{* * *}$ & 1.70 & $1.23-2.34^{* *}$ & 1.71 & $1.24-2.37^{\star \star}$ \\
\hline \multicolumn{7}{|l|}{ Religion } \\
\hline No & 1 & Reference & 1 & Reference & 1 & Reference \\
\hline Yes & 0.95 & $0.80-1.13$ & 1.02 & $0.85-1.23$ & 0.99 & $0.83-1.20$ \\
\hline \multicolumn{7}{|l|}{ Care experience } \\
\hline No & 1 & Reference & - & - & 1 & Reference \\
\hline Yes & 0.66 & $0.54-0.82^{* * *}$ & - & - & 1.54 & $1.22-1.95^{* *}$ \\
\hline \multicolumn{7}{|l|}{ Care cost } \\
\hline$<\$ 2,000$ & 1 & Reference & - & - & 1 & Reference \\
\hline$>\$ 2,000$ & 0.86 & $0.65-1.12$ & - & - & 0.97 & $0.71-1.32$ \\
\hline \multicolumn{7}{|c|}{ Cancer patients among family/friends } \\
\hline No & 1 & Reference & - & - & 1 & Reference \\
\hline Yes & 0.99 & $0.83-1.18$ & - & - & 0.93 & $0.77-1.12$ \\
\hline
\end{tabular}

OR, odds ratio; $\mathrm{CI}$, confidence interval. ${ }^{* * *} \mathrm{p}<0.001,{ }^{* *} \mathrm{p}<0.01$.

cancer negatively, and this can influence the behavior towards cancer survivors. These negative perceptions may hinder the cancer survivor's re-assimilation into society (specifically the workplace) [2]. Current research holds that attitudes are formed through learning, rather than as innate states [11]. Based on that, negative attitudes towards cancer survivors returning to work require appropriate intervention (supportive workplace environment intervention), education (rehabilitation programs and training) and social support (advocacy campaigns).

The factors influencing negative attitudes of the public towards cancer survivors returning to work included region, cancer patient care experience, and monthly income. Nega- tive perceptions were higher among those living in urban/ rural areas than in metropolitan areas, and lower education levels and socio-economic status measures, such as monthly income and living area, were associated with negative attitudes or with discrimination experiences [12]. Negative attitudes towards cancer survivors returning to work prevailed in rural areas, partly because rural residents are predisposed to believe that physical limitations among cancer survivors contribute to lower work productivity [13]. Sowden et al. [14] showed that labor is more physically demanding in rural areas than in cities, and rural cancer survivors are more likely to retire early. In Finland, however, the capabilities of cancer survivors to work were not different from those of demo- 
graphically matched healthy controls, and the ability of survivors diagnosed two years previously to engage in physical work had deteriorated by $26 \%$ [15]. In the United States, some prostate cancer patients reported that 12 months after diagnosis, cancer and its treatment interfered with physical functioning at work (22\%-30\%) [16]. A recent Australian study reported a similar trend in health-related quality of life 12 months after treatment for breast cancer survivors living in urban areas [17]. Since accessibility to medical systems is lower in rural areas, rural residents tend to have a greater negative perception of cancer survivors returning to work [18]. Overseas studies show that, compared with metropolitan residents, urban/rural residents face challenges in accessing medical care and necessary support services due to extensive and sometimes difficult travel, as well as limited health care facilities [19]. In Korea, rural residents face unequal access to medical services [20], posing limitations for cancer survivors needing frequent care. Thus, residents in rural areas tend to have more negative perceptions of cancer survivors rejoining society, since those with cancer are expected to have trouble with recovery. To resolve these negative perceptions among rural residents, a communitybased social support system is necessary.

The public's negative attitudes towards cancer survivors returning to work were significantly higher among those who had patient care experience. The increasing number of cancer patients leads to an increasing burden on caregivers of cancer patients. Family members of cancer patients are not only their primary support, both mentally and socially, but also active participants in the patient's care and recovery, rather than passive observers. In addition, caregivers need to take care of cancer patients constantly during the treatment process, which includes surgery, chemotherapy, and radiation therapy; they also must endure the treatmentinduced complications and pain experienced by the patients. Moreover, high levels of burden and distress comparable to those experienced by caregivers of patients with dementia [21] and acquired immune deficiency syndrome are often reported [22]. Some people feel uncomfortable in the presence of cancer patients, who are sometimes victimized or avoided by family members and friends, distressing cancer patients and their family and friends. In particular, the burden of cancer patient care was relatively high in Korea, in that $82.2 \%$ of family caregivers exhibited symptoms of depression, $38.1 \%$ had symptoms of insecurity, $17.7 \%$ felt the impulse to commit suicide, and $2.8 \%$ actually attempted to commit suicide [23]. Among caregiver support activities, there are numerous caregiver management programs in other countries for caregiver distress management. For instance, the Oncology Nursing Society in the United States published a research report for evidence-based practices regarding stress and burnout levels of cancer patient care- givers [24]; yet, South Korea still lacks support programs or guidelines for caregivers. Because most patient care begins one to two years post-diagnosis, when intensive treatment is given, support services for distressed caregivers suffering from insecurities and depression are not provided or managed in a timely manner. Therefore, the attitudes regarding the recovery, social contribution and return to work of cancer survivors are negative. In the future, intervention programs for respective types of stress should be provided to caregivers on an individual basis during and after treatment.

In this study, those with higher incomes showed more negative attitudes towards cancer survivors returning to work. In previous studies of the stigmas faced by cancer patients, negative attitudes were found to be associated with lower socioeconomic levels [12]. However, few studies have evaluated the relationship between socioeconomic levels and the factors related to public attitudes towards cancer survivors returning to work, the topic of this study. Therefore, crosscultural studies across developing countries, including Korea, and developed countries should be conducted.

This study had several limitations. The survey response rate of $20.7 \%$ was deemed to be quite low. The potential reasons for this include, first, the low contact rate of $51.0 \%$. With an increase in single and dual income families, the investigators could not meet all household members. In addition, because most families live in apartments, the barriers to entry were high. Second, since the survey focused on middle-aged people with plenty of experience in social activities regarding attitudes towards cancer survivors returning to work, it failed to assess the attitudes of those in their 20s and 30s; thus, the survey population was not representative of the entire South Korean population.

\section{Conclusion}

In summary, this study identified negative attitudes towards cancer survivors returning to work in South Korea and the factors influencing the reintegration of cancer survivors into society. The associated factors included those related to socio-economic status. As the perceptions of rural residents were found to be negative, a community-based social support approach is necessary. Regarding personal factors, negative attitudes were high among those with patient care experience, which suggests a need for intervention at the level of the individual caregiver. 


\section{Conflicts of Interest}

Conflict of interest relevant to this article was not reported.

\section{Acknowledgments}

This study was supported by a grant from the National Cancer Center (Grant number 1210151), Republic of Korea. The funders had no role in study design, data collection and analysis, decision to publish, or preparation of the manuscript.

\section{References}

1. Jung KW, Won YJ, Kong HJ, Oh CM, Seo HG, Lee JS. Cancer statistics in Korea: incidence, mortality, survival and prevalence in 2010. Cancer Res Treat. 2013;45:1-14.

2. Chen HM, Tan WH, Tan WC, Yu CK, Lim TH, Tay MH, et al. Attitudes towards cancer survivors: a small survey. Singapore Med J. 2006;47:143-6.

3. Park JH, Park EC, Park JH, Kim SG, Lee SY. Job loss and re-employment of cancer patients in Korean employees: a nationwide retrospective cohort study. J Clin Oncol.2008;26: 1302-9.

4. Hoving JL, Broekhuizen ML, Frings-Dresen MH. Return to work of breast cancer survivors: a systematic review of intervention studies. BMC Cancer. 2009;9:117.

5. Yabroff KR, Lawrence WF, Clauser S, Davis WW, Brown ML. Burden of illness in cancer survivors: findings from a population-based national sample. J Natl Cancer Inst. 2004;96: 1322-30.

6. Else-Quest NM, LoConte NK, Schiller JH, Hyde JS. Perceived stigma, self-blame, and adjustment among lung, breast and prostate cancer patients. Psychol Health. 2009;24:949-64.

7. Cho J, Smith K, Choi EK, Kim IR, Chang YJ, Park HY, et al. Public attitudes toward cancer and cancer patients: a national survey in Korea. Psychooncology. 2013;22:605-13.

8. Mosher CE, Danoff-Berg S. Death anxiety and cancer-related stigma: a terror management analysis. Death Stud. 2007;31: 885-907.

9. Wilson K, Luker KA. At home in hospital? Interaction and stigma in people affected by cancer. Soc Sci Med. 2006;62: 1616-27.

10. Lepore SJ. A social-cognitive processing model of emotional adjustment to cancer. In: Baum A, Andersen BL, editors. Psychosocial interventions for cancer. Washington, DC: American Psychological Association; 2001. p. 99-116.

11. Allport GW. Attitudes. In: Murchison C, editor. Handbook of social psychology. Worchester, MA: Clark University Press; 1935. p. 785-844.

12. Kagawa-Singer M, Padilla GV, Ashing-Giwa K. Health-related quality of life and culture. Semin Oncol Nurs. 2010;26:59-67.

13. Taskila T, Lindbohm ML. Factors affecting cancer survivors' employment and work ability. Acta Oncol. 2007;46:446-51.

14. Sowden M, Vacek P, Geller BM. The impact of cancer diagnosis on employment: is there a difference between rural and urban populations? J Cancer Surviv. 2014;8:213-7.

15. Taskila T, Martikainen R, Hietanen P, Lindbohm ML. Comparative study of work ability between cancer survivors and their referents. Eur J Cancer. 2007;43:914-20.

16. Bradley CJ, Neumark D, Luo Z, Bednarek H, Schenk M. Employment outcomes of men treated for prostate cancer. J Natl Cancer Inst. 2005;97:958-65.

17. DiSipio T, Hayes SC, Newman B, Aitken J, Janda M. Does quality of life among breast cancer survivors one year after diagnosis differ depending on urban and non-urban residence? A comparative study. Health Qual Life Outcomes. 2010;8:3.

18. Weaver KE, Geiger AM, Lu L, Case LD. Rural-urban disparities in health status among US cancer survivors. Cancer. 2013; 119:1050-7.

19. Beck SL, Towsley GL, Caserta MS, Lindau K, Dudley WN. Symptom experiences and quality of life of rural and urban older adult cancer survivors. Cancer Nurs. 2009;32:359-69.

20. Lee YJ. An study on the inepuality of health care resources distribution affected by regional characteristics. Crit Soc Welf Acad. 2005;21:49-78.

21. Kim Y, Schulz R. Family caregivers' strains: comparative analysis of cancer caregiving with dementia, diabetes, and frail elderly caregiving. J Aging Health. 2008;20:483-503.

22. Stetz KM, Brown MA. Physical and psychosocial health in family caregiving: a comparison of AIDS and cancer caregivers. Public Health Nurs. 2004;21:533-40.

23. Park B, Kim SY, Shin JY, Sanson-Fisher RW, Shin DW, Cho J, et al. Suicidal ideation and suicide attempts in anxious or depressed family caregivers of patients with cancer: a nationwide survey in Korea. PLoS One. 2013;8:e60230.

24. Honea NJ, Brintnall R, Given B, Sherwood P, Colao DB, Somers SC, et al. Putting Evidence into Practice: nursing assessment and interventions to reduce family caregiver strain and burden. Clin J Oncol Nurs. 2008;12:507-16. 